\title{
The prospect of low-cost housing provision by the private sector: a case study on the urban poor in Bangkok
}

\author{
N. Sahachaisaeree \\ Department of Urban and Regional Planning, \\ King Mongkut's Institute of Technology Ladkrabang, Bangkok, Thailand
}

\begin{abstract}
Spontaneous settlement has been a major problem for Third World cities since the 1940s. Urban low cost housing not only helps solve the housing deficiency issue in the cities, but it also helps ease the cost of labour and amplify the level of industrial development as well. State intervention on housing provision could hardly solve the problem, since it requires large amounts of fiscal budget and efforts. The research aims to investigate the possibility of involving the private sector to provide low-cost housing to the urban poor. The study applied a questionnaire survey on 1,000 low-income households from the Bangkok inner city, suburban Bangkok, and outer Bangkok, together with 88 real-estate firms in various sizes and classes to obtain data matching the needs of the urban poor with the interest of private sectors to join the program. The study found that most real estate operators agreed with the collaborative ideas but not necessarily wanted to join the program. The study found that the Baht $350,000-500,000$ range of price was most feasible for private public collaboration to provide housing for the urban poor in Bangkok. For housing types, the private sector was mostly interested in doing projects in the condominium and flat types. For incentives, the private sector gave priority to the connection of utilities, the relaxation of development control, tax reduction on commercial tax, and relaxation on the property transfer tax respectively. The study suggested that outer Bangkok would be an ideal location for potential schemes to cut land cost. Since the most attractive incentive was title deed transfer tax break, followed by exile tax reduction, relaxation of estate and building regulation, and the right to public utilities and infrastructure connections.
\end{abstract}

Keywords: low-cost housing, urban poor, public-private partnership. 


\section{Introduction}

A number of empirical facts confirmed that the provision of low-cost housing for the urban poor has been a crucial factor enhancing the national industrial development by means of the availability of cheap labor. Such arrangements via the bureaucratic institutions, however, were proved financially unproductive and inaccessible for the targeted bottom class, owing to the World Bank's cost recovery approach taken by policy makers and the lack of market competition. Housing approach within the market economy could be categorized into two different perspectives - basic needs and commodity (Sahachaisaeree [1]).

The former approach viewed housing as a means of survival to meet the human biological needs. The state thus had the legitimacy to provide housing for the neediest group of citizens at subsidized cost or even free of charge. The later approach, however, looked at housing as an economic means of capitalist accumulation. Provision of housing to the poor could mean spending tax money to a particular group of individual unduly. The Thai government attempted to integrate both approaches to manage its housing provision to the population at large by means of the National Housing Authority. However, the arrangement could reach only the lower-middle income group, while the poorest group has been left out and currently being served by the Ban Munkong Upgrading program. Again, a number of empirical researches pointed to the fact that the private sector could play an important role to fill the gap, provided that the state offers sufficient and appropriate incentives to the private sector.

This research thus aimed to study the social behavior and the extent of ability to pay for urban housing among the urban poorest group, the prospect of crosssubsidization scheme for the private sector to ease the burden of public sector, and the prospect of incentives motivating the private sector to provide low-cost housing in the city. This article comprised four major sections. The first section established the theoretical background of the research. The second section outlined the framework for the study. The third section presented the research methodology. And the final section outlined the finding and recommendation of the research.

\section{Theoretical background}

A number of thoughts regarding urban housing have been developed during the past decades set within the market economy and socialist contexts. The self-help method of housing for the urban poor has started and transformed along the line of Third World political and economic transition Sahachaisaeree [2]. While the Demolitionist Approach in the 1950s viewed spontaneous settlement as parasitic, causing massive resistance and political chaos, the Supportive Approach has been developed in the 1970s by John F.C. Turner integrating the empowerment of the state and the obligation of the urban poor to self-provide shelters for the community. The state played merely a supportive role, providing public utilities and initial funding to the poorest communities [3]. The World Bank adopted Turner's view and transformed it in accordance with its own market economy 
ideology. Turner's idea, nonetheless, conflicted with the World Bank approach, which supported state intervention and the cost recovery process [4]. Rod Burgess, on the other hand, argued that Turner's self-help idea only allowed the state to exploit the urban poor's free labor to self-provide for its own labor reproduction, while the scheme was still working within the system of market economy, reinforcing the capitalist logic and overlooked the conflict among modes of production under the market ideology [5]. The loan meant to merely strengthen the market mechanism and minimize the bottleneck of housing delivery World Bank [7]. It is obvious that while Turner endeavored to allocate and distribute the limited resources among members of the community, the World Bank resorted to the market mechanism paying little attention to the issues of land tenure and infrastructure (Burgess $[6,8]$ ). Together with the IMF, the World Bank then turned its attention to structural transformation, focusing on the macro economic growth instead of dealing with the petty projects at the local level (Foxley [9]; Yagci et al. [10]). The approach then ignored the housing issue in the Third World cities, but rather focused on the ability to pay of the dwellers (TUE [11]). Finally, the Collaborative Approach focused on the limitation of the institution and the imperfect market, instead of only the participation of the urban poor (Safler [12]). In the late 1980s, the United Nations Center for Human Settlements (UNCHS, Habitat) focused on the collaboration among the state, the market, the NGOs and the community to "enhance" the capability of the community (UNCSH [13]). The approach thus integrated the concept of good governance and supportive means of housing provision to the solution of low cost housing in the Third World cities.

\section{Research framework}

This research thus took the position of Collaborative Approach to discover a prospect solution of the provision of housing for the urban poor. There has been a body of literature illustrating the success of private-public partnership, by means of cross subsidies and tax incentives, to solve the problems of low income housing needs (Kwitko [14]). The collaborative approach could help save fiscal budget on low-cost housing in the long run, yield a better efficiency in the provision process, partially preventing kick-back and official corruption at the state and project level. One might argue that the approach still cannot reach the poorest (homeless) group in the city; in fact, the approach could save part of the fiscal budget for slum upgrading and utilities subsidization. And most of all, the approach could prevent 'popular policy' claimed by politicians at the national level. However, there had yet research of this kind to explore the collaborative possibility in the Thai context. This research thus aimed to explore the social behavior and the extent of ability to pay for urban housing among the urban poorest group, the possibility of cross-subsidization within the conventional housing project to for the private sector to ease the burden of public sector, and the types of incentives being able to motivate the private sector to collaborate with the public sector to provide low-cost housing in the city. 
Derived from the existing housing situation in Bangkok and the theoretical setting established in the last section, the conceptual framework attempted to explain the relationship among variables which link the urban poor's needs and the interest of the private sectors (Figure 1). The research hypothesized that familial attributes of low-income households governs the needs and characteristics of housing on the one hand, and the incentive offered by the state which was able to convince the private sector to produce housing stock to meet the needs of low income household on the other.

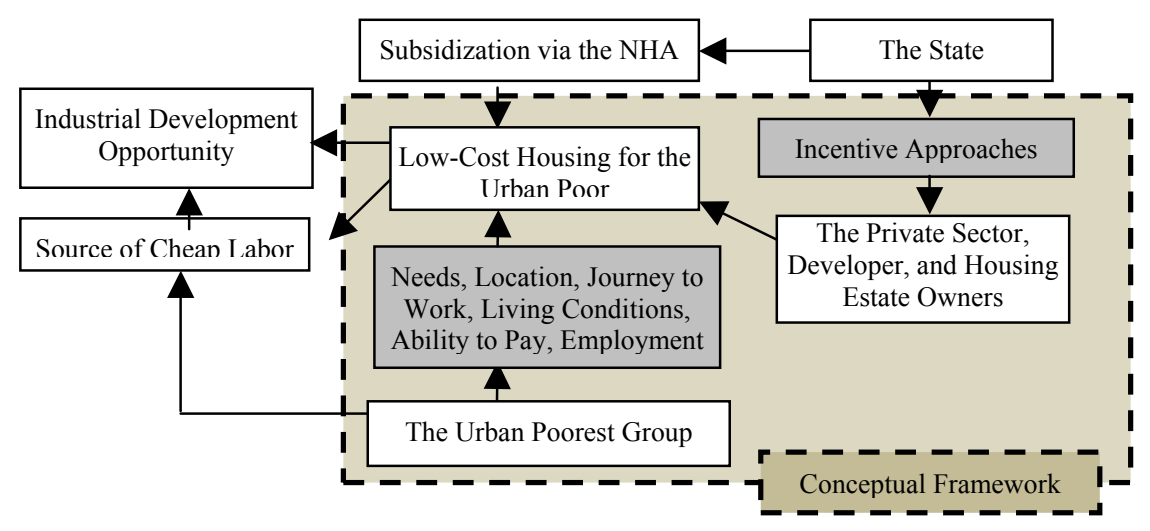

Figure 1: Conceptual framework of the study.

\section{Methodology}

Under the framework of the study shown in figure 2, the study was designed to apply data from 1,000 low-income households from the Bangkok inner city, suburban Bangkok, and outer Bangkok, to obtain housing needs and ability to pay of the urban poor. A second survey was conducted with 88 real-estate firms in various sizes and classes to discover the attitude of private sector and their prospect to participate in the program. It also aimed to reveal the level and the type of incentives that attract the private sector to join the program. Finally, an in-depth interview with the public sector was conducted to derive the institutional situations that would determine the prospect of housing provision by the private sector.

A multi-state sampling was applied to randomly draw low-income household samples from the three areas of Bangkok, namely, Inner-Middle- and OuterBangkok. A total of thirty-three low-income communities were drawn to represent the whole Bangkok area and its vicinity. Respondents were then randomly sampled from 4 types of settlements: spontaneous settlement, affordable housing schemes, recent NHA relocation program, and the former NHA housing schemes, covering the three afore mentioned spatial settings. 


\section{Findings of the study}

Since the study attempts to investigate, compare, and join housing needs of the urban poor, on the one hand, and the interest of the private sector on the other; this section delineate findings from both sides separately in order to reach a policy implication at the final section.

\subsection{The urban poor's needs}

\subsubsection{To what extent was the housing location determined by dweller's job?}

The study found that the urban poor were mostly migrants from rural areas, seeking to reside close to their employment or with their next of kin or social faction. The lower the level of socioeconomic status the longer they travel to work, for instance, spontaneous settlement and NHA relocation programs had and average distance of travel significantly longer than the rest of the groups. Low income households in the outer Bangkok tended to travel longer to their employment than those live in the inner city. Daily wage workers were found living nearest to their job due to the characteristics of their employment which were mostly manual oriented and require long hour of working period, Types of employment also significantly governed their housing locations, especially street vendors who needed to live close to their employment. Other members of the lower income families tended to change their employment to minimize travel cost and time. The study also found that the lowest income group tended to need housing most adjacent to their job.

\subsubsection{What housing types did the urban poor need?}

The study found that the type of housing which are most suitable for the urban poor's lifestyle and employment were detached house, shop house, and town house. Apartment houses and flats were least suitable due to the unique characteristics of familial structure and the urban poor's type of employment, which needed additional space for cooking and other economic activities. The size of housing was also found correspond with familial structure in that larger family tended to need more space than smaller ones. Requirement on unit size was found in contrast with the extend of ability to pay, namely, poorer families tended to be larger and need more dwelling space

\subsubsection{To what extent the urban poor could pay for their housing?}

The group with lowest income holds the highest needs for low-cost housing, which circumstance extensively impaired the social mobility of the group. Level of education, type of employment, and level of income were also found related with their ability to pay for monthly rents and down payment for hire purchasing. For monthly installment, dwellers with lowest ability to pay were found in the "spontaneous" and "affordable housing" communities who can afford to pay the amount of 1,808 and 1,905 baht per month respectively. In contrast, communities with highest ability to pay were "the former NHA housing schemes" (3,377 baht) and those in the "relocation program" (2,802 baht). For down payment, "affordable housing" is found the community with least ability (9,488 baht) follows by "spontaneous" (14,555 baht). The low willingness to pay for those 
who resided in the "affordable housing" might stem from the recent standard of payment set by the Thaksin administration's popular policy. Those who live in the "relocation program" were the group with least ability to pay. The area with highest willingness to pay has been the "spontaneous" and "NHA housing" communities, 29,007 and 65,520 baht respectively. The spontaneous group were mostly facing eviction and were willing to pay for their dwelling out of desperation, while those who live in the NHA housing were the most well off ones. Beside family income, level of education and employment are found significantly correlated with the ability to pay. The multiple regression of 10 variables shows that monthly income explains only $10 \%$ of the ability to pay. Family income, level of education, age, housing expenditure, and family size explain $33 \%$ of the down payment. It could be implied that low-cost housing provision policy should not be determined solely by the ability to pay of the urban poor, but also by their genuine needs.

\subsubsection{What were the urban poor's potential to move upward in their social ladder?}

The study found that dwellers in the spontaneous communities were least capable of supporting their children's education, especially in the higher level. Education at the compulsory level still require a large amount of time from the working children and a large number of them dropout of school to help their parents make a living. Detailed discussion was presented elsewhere (Sahachaisaeree [15]). The spontaneous communities are found the most severe group who were in need of housing with the least ability to pay. Relocation, by all means, impaired their life chance due to lengthy travel time and lack of working space within their homes. Both limitations are obstacles to dwellers' social mobility and need more attention from the public sector.

\subsubsection{How much chance did the urban poor join the low-cost housing program?}

Most urban poor voiced their willingness to join any low-cost housing program, provided that they could complement their economic and social needs. The obstacle preventing the urban poor to join the program has been the distance from employment, the ability to pay monthly installment, the lack of public transportation connecting their home and workplace, the insufficiency of dwelling space, and the lack of public utilities. However the urban poor's needs differed due to the difference of their economic and familial situations. The spontaneous community's concerns are mainly on the location away from employment and the ability to pay. The most important factors are proximity to public services, commercial centers, convenient stores, educational institutions, and public transportation respectively.

\subsection{The private sector's potential to collaborate}

\subsubsection{Where should the affordable housing scheme be located?}

The study found that most conventional real estate developers agreed with the collaborative ideas; $88 \%$ of them agreed with the private-public partnership method, which showed the positive prospect of low-cost housing provision by 
the private sector. However, real estate sector had little understanding on the pattern of urban dynamic, which in turn, impaired their vision and state of decision making on their investment. The significant of low-cost housing on the development of the urban secondary and tertiary sectors, for instance, was not entirely realized by the real estate sector. Due to higher land price in the inner city, developers in outer Bangkok were more approved of the idea than those in the inner city and middle Bangkok; a large portion of them voiced their view to carry out the projects at outer Bangkok or outer province to minimize cost. In terms of community diversity, most developers were consent with the idea to combine the income groups or locate the low income households in the nearby neighborhood; $77 \%$ of the respondents agreed with the concept of neighborhood diversity. Only the high-end developers wanted to detach the low-income program from their present ones to maintain their reputation. Lack of urban amenity at the outer Bangkok has been the major obstacle discouraging developers to join the program. When looking at the type and classes of real estate operator, the low and medium classes, mostly large projects owners of detached-house and condominium types located in Bangkok's vicinity, tended to agree more on partnership than did the higher class project operators. In this light, owners of the higher class projects tended to see the low-cost housing alternative as unnecessary burden and tended to value tax incentives in a lesser extent than did owners in the lower class project. Most operators wanted the lowincome housing to be separated from their present estate and located in the relatively more remote areas of vicinity or even outer provinces in order to maintain their "high-class" reputation.

\subsubsection{What type of firm is willing to join the collaborative program?}

Despite of the consent of the majority, $(89 \%$ of them agree with the collaborative approach but not necessary wanted to join the program), especially some large and high-end firms did not agree with the collaborative ideas. Most real estate providers perceived the higher cost of land in the urban area and the difficulty to break even in their investment on low-cost housing as major obstacles. Categorized by firm size and project level, those serving the medium-low income group (below 10 million baht/unit) expressed their positive intention. Small to medium projects operators below 100 units and 300-500 units tended to agree, in order to avoid competing with the present public affordable housing projects. The most promising providers to match the public-private partnership were the lower class of housing estate operators (1-5 million Baht/unit). Highend projects (20-30 million per unit) and larger projects (over 500 units) mostly expressed their negative intention to collaborate. Location wise, projects located in the middle and outer Bangkok were those who most approved while projects in Bangkok inner city were those who least agreed with the proposition, since location tended to be correlated with unit cost of housing units due to high land cost (Table 1).

\subsubsection{What is the feasible housing cost per unit?}

Cost per unit was highly dependent on the location and types of housing due to land and construction costs. However, the study found at least two groups of 
feasible price level, which were acceptable for the estate operators to build lowcost housing for the urban poor (Baht 350,000-500,000 and Baht 800,000$1,000,000)$. Inner city projects were estimated approximately 800,000 to $1,000,000$ baht per unit provided that there was without land and financial subsidizations. Obviously, such price level was unaffordable for the urban poor. Projects located at outer Bangkok or outer province could cost below 350,000 baht per unit. Estimated cost was also dependent on characteristics of developers, low-end and outer Bangkok were more positive in cost assessment. In short, the most feasible cost of housing would be 350,000-500,000 Baht.

Table 1: $\quad$ Location and collaboration.

\begin{tabular}{|c|c|c|c|}
\hline \multirow{2}{*}{ Project location } & \multicolumn{2}{|c|}{ Public private collaboration } & \multirow{2}{*}{ Total } \\
\cline { 2 - 3 } & agree & disagree & \\
\hline Inner Bangkok & $80.0 \%$ & $20.0 \%$ & $100.0 \%$ \\
\hline Middle Bangkok & $80.0 \%$ & $20.0 \%$ & $100.0 \%$ \\
\hline Outer Bangkok & $100.0 \%$ & & $100.0 \%$ \\
\hline Total & $88.9 \%$ & $11.1 \%$ & $100.0 \%$ \\
\hline
\end{tabular}

Table 2: $\quad$ Feasible housing cost.

\begin{tabular}{|c|c|c|c|c|c|c|c|}
\hline \multirow[b]{2}{*}{$\begin{array}{l}\text { Location of low- } \\
\text { cost housing }\end{array}$} & \multicolumn{6}{|c|}{ Level of low-cost housing (baht) } & \multirow[b]{2}{*}{ Total } \\
\hline & $\begin{array}{l}\text { Below } \\
350,000\end{array}$ & $\begin{array}{c}350,001 \\
- \\
500,000\end{array}$ & \begin{tabular}{|c|}
500,001 \\
- \\
650,000
\end{tabular} & $\begin{array}{c}650,001 \\
- \\
800,000\end{array}$ & $\begin{array}{c}800,001 \\
- \\
1,000,000\end{array}$ & $\begin{array}{l}1,000,000 \\
\text { and above }\end{array}$ & \\
\hline Inner Bangkok & - & - & $33.3 \%$ & - & $66.7 \%$ & - & $100 \%$ \\
\hline Outer Bangkok & - & $25.0 \%$ & - & $8.3 \%$ & $50.0 \%$ & $16.7 \%$ & $100 \%$ \\
\hline Outer province & $50.0 \%$ & - & - & - & - & $50.0 \%$ & $100 \%$ \\
\hline Total & $5.9 \%$ & $17.6 \%$ & $5.9 \%$ & $5.9 \%$ & $47.1 \%$ & $17.6 \%$ & $100 \%$ \\
\hline
\end{tabular}

For housing types, the private sector were mostly interested in doing projects in the condominium and flat types believing that they were most feasible in terms of profit making. Detached house and town house were categories seeing least realistic. The reasons they chose condominiums and flats are because they were relatively high in density, which could minimize land and utility costs. Flats were more favorable, since it could trade off the lower cost with larger dwelling size (Table 2).

\subsubsection{What incentives were most attractive for the real estate operators?}

There were two types of support as incentives: Financial support and other types of benefit. For financial support (loan and subsidies), the study found that $18 \%$ of the affordable housing investment contributed to utility provision, while the rest of $82 \%$ has been the portion loan from the government to build the structure. 
The developers then delivered the housing to the potential dwellers, and conveyed the dwellers to commercial bank to pay long-term installment. The research found that the private sector needed financial support in the form of soft loan with low interest for such activities. The amount of per-unit-loan would be up to 315,200 Baht out of the 350,000 housing unit cost. Among the four other types of potential incentives, the research found that the private sector gave priority to the connection of utilities, the relaxation of development control, tax reduction on commercial tax, and relaxation on the property transfer tax respectively. However, there were still some location differences among projects, developers in the middle Bangkok and outer province gave first priority on the relaxation of commercial tax, while the outer Bangkok developers considered utility connection the most important incentive.

\subsection{The potential policy implications}

Despite of the difficulty of provision via public-private partnership for the poorest group, the private real estate operators in the 1-5 million Baht/unit cluster were prime target to be encouraged to provide housing for the Baht 350,000 type of housing, while the NHA should be assigned to provide for the poorest class. To mitigate the land cost issue, remote location for low-cost housing should be clustered to gain benefit from agglomeration, economical facility provision, and mass-transit connection between inner city and the vicinity. In this light, outer Bangkok would be an ideal location for potential schemes to cut land cost. Since the most attractive incentive was title deed transfer tax break, followed by exile tax reduction, relaxation of estate and building regulation, and the right to public utilities and infrastructure connections, the public sector should consider the possibility to provide tax incentives on such categories while endeavor to provide public utilities to facilitate the schemes.

\section{Conclusion}

Despite a number of disagreements between the needs of occupants and the developers: location, unit cost, unit size, utilities, urban amenities, etc. it was still highly feasible for the private sector to provide low-cost housing with the intervention of the state, on the reason that the low-cost housing was a means to help ease the burden of labor cost in the industrial sector. Since ability to pay did not match the willingness of provider, subsidization from the state was still needed. The state / the NHA should make readjustment to target the neediest group of urban poor instead of merely helping those with the ability to pay. The public sector needed some modification on its housing service strategies, considering more on public-private partnership rather than dependent merely on services provided by the NHA. The academia and planners should endeavor to educate and transform the attitude of public personals and private sector operators to better understand the social behavior of the urban poor and the advantage of low-cost housing provision upon the industrial sector. 


\section{References}

[1] Sahachaisaeree, N, The Political Economy of Land and Housing for the Urban Poor in Bangkok: A Case Study in Klong Toey and Wat Chonglom Settlement, Ph.D. Dissertation, Univ. of Hawaii-Manoa, 1995

[2] Sahachaisaeree, N., Problems and evolution of paradigm in low-cost housing provision in Third-World cities. Proc. of the Symposium on urban development, Chulalongkorn University, Bangkok, 2000.

[3] Turner, J., Housing by People. Towards Autonomy in Building Environments, Marion Boyer: London, 1976.

[4] Turner, J., Future directions in housing policies. Habitat International, 10(3), pp 7-25, 1987.

[5] Burgess, R., Petty commodity housing or dweller control? A critique of the work of John F.C. Turner. World Development, 6(9/10), pp.1105-1133, 1978.

[6] Burgess, R., The limits of self-help housing. Development and Change, 16(2), pp. 271-312, 1985.

[7] World Bank, Housing Sector Paper, World Bank: Washington D.C., 1975.

[8] Burgess, R., the International Sponsorship of Self-Help Housing and the Reproduction of Labor Power Theory, AAGS: London, 1985.

[9] Foxley, A. Latin American Experiments in Neoconservative Economics, University of California Press: Berkeley, Los Angeles, 1983.

[10] Yagci, F., Kamin, S. \& Rosenbaum, V., Structural Adjustment Lending: An Evaluation of Program Design. World Bank Staff Working Papers No. 735, World Bank: Washington D.C., pp. 1-33, 1985.

[11] TUE (The Urban Edge), Housing, Macro Policies: Tracing the Links, 12(3), 1988.

[12] Safler, M., The passage to positive planning. Habitat International, 7(5/6), 1983.

[13] UNCSH (United Nations Center for Human Settlements), the Global Strategy for Shelter to the Year 2000, UNCSH: Nairobi, 1990.

[14] Kwitko, L., The dynamics of shelter in Hong Kong: local manifestations and global linkages. A MURP Paper, Department of Urban and Regional Planning, Univ. of Hawaii-Manoa, 1989.

[15] Sahachaisaeree, N., Urban housing and the extent of social mobility of the urban poor: A case study on the urban low-income communities in Bangkok. Journal of the Faculty of Architecture, KMITL, 3(1), 2006. 